\title{
Future Internet technologies for Environmental Applications
}

Carlos Granell ${ }^{1}$, Denis Havlik ${ }^{2,}$, , Sven Schade ${ }^{3}$, Zoheir Sabeur ${ }^{4}$, Conor Delaney ${ }^{3}$, Jasmin Pielorz ${ }^{2}$, Thomas Usländer ${ }^{5}$, Paolo Mazzetti ${ }^{6}$, Katharina Schleidt ${ }^{7}$, Mike Kobernus ${ }^{8}$, Fuada Havlik², Nils Rune Bodsberg ${ }^{9}$, Arne Berre ${ }^{9}$, Jose Lorenzo Mon ${ }^{10}$

${ }^{1}$ Universitat Jaume I of Castellón, Spain. Carlos Granell was affiliated with European Commission, Joint Research Centre during the project.

${ }^{2}$ Austrian Institute of Technology (AIT), Austria. Jasmin Pielorz was affiliated with Ubimet GmbH, Vienna during the project.

${ }^{3}$ European Commission, Joint Research Centre (JRC), Italy

${ }^{4}$ University of Southampton IT Innovation Centre, Electronics and Computer Science, Faculty of Physical Sciences and Engineering, United Kingdom

${ }^{5}$ Fraunhofer IOSB, Germany

${ }^{6}$ National Research Council of Italy - Institute of Atmospheric Pollution Research, Italy

${ }^{7}$ Umweltbundesamt GmbH, Austria

${ }^{8}$ Norsk institutt for luftforskning (NILU), Norway

${ }^{9}$ SINTEF, Norway

${ }^{10}$ Atos Spain, Spain

*Corresponding author, (denis.havlik@ait.ac.at)

This paper can be cited as:

C. Granell, D. Havlik, S. Schade, Z. Sabeur, C. Delaney, J. Pielorz, T. Usländer, P. Mazzetti, K. Schleidt, M. Kobernus, F. Havlik, N.R. Bodsberg, A. Berre, J. Lorenzo Mon. Future Internet technologies for Environmental Applications. Environmental Modelling and Software, 78:1-15, 2016, ISSN 1364-8152.

http://dx.doi.org/10.1016/j.envsoft.2015.12.015 


\title{
Future Internet technologies for Environmental Applications
}

\begin{abstract}
This paper investigates the usability of Future Internet technologies (aka "Generic Enablers of the Future Internet") in the context of environmental applications. The paper incorporates the best aspects of the state-of-the-art in environmental informatics with geospatial solutions and scalable processing capabilities of Internet-based tools. It specifically targets the promotion of the "Environmental Observation Web" as an observation-centric paradigm for building the next generation of environmental applications. In the Environmental Observation Web, the great majority of data are considered as observations. These can be generated from sensors (hardware), numerical simulations (models), as well as by humans (human sensors). Independently from the observation provenance and application scope, data can be represented and processed in a standardised way in order to understand environmental processes and their interdependencies. The development of cross-domain applications is then leveraged by technologies such as Cloud Computing, Internet of Things, Big Data Processing and Analytics. For example, "the cloud" can satisfy the peak-performance needs of applications which may occasionally use large amounts of processing power at a fraction of the price of a dedicated server farm. The paper also addresses the need for Specific Enablers that connect mainstream Future Internet capabilities with sensor and geospatial technologies. Main categories of such Specific Enablers are described with an overall architectural approach for developing environmental applications and exemplar use cases.
\end{abstract}

Keywords: Environmental Informatics; Environmental Observation Web; Future Internet; Cloud Computing, Internet of Things, Big Data, Environmental Specific Enablers; Volunteered Geographic Information; Crowdtasking 


\section{Software and/or data availability:}

Name of software: Future Internet Generic Enablers (http://catalogue.fiware.org); Specific Enablers for Environment (http://catalogue.envirofi.eu)

Developers: The FI-WARE and ENVIROFI Consortia.

Contact information: Those interested should address individual project partners responsible of each specific enabler and/or application as indicated on the FI-WARE and ENVIROFI catalogue sites.

Hardware required: Smartphone device for mobile applications; computer (farm) for the backend.

Software required: Android or Internet browser for the GUI components; Linux or Windows OS (usually hosted on "the cloud") for backend.

Program language: Multiple programming languages.

Availability and cost: Users can access directly to the catalogue to download Generic and Specific Enablers, applications, technical documents and user manuals. Please note that not all enablers have the same status of implementation, maturity or user licensing. 


\section{Introduction}

In the course of the past four decades, we have witnessed a continuous evolution of geospatial information technologies for the support of earth and environmental sciences (Budhathoki et al., 2008). Starting from enhanced Geospatial Information System (GIS) desktop solutions, via Spatial Data Infrastructures (SDIs) of varying maturity, we are moving towards innovative technologies to realise the next-generation Digital Earth vision (Goodchild et al., 2012). Now, the pervasive connectivity promised by the Cloud Computing paradigm, the Internet of Things (IoT) phenomenon, and Big Data innovations might lead to disruptive changes in the design and development of dataintensive applications (Douglas, 2001). In this article, we will refer to a set of related emerging technology and standards as the Future Internet (FI).

Environmental applications often process large collections of data sets. Earth Observation data, from sensors with ever-growing spatial, temporal and radiometric resolution, gets combined with complex environmental models and simulations at all scales. Until recently, such processing chains were unthinkable without domain-specific technology and tailored solutions to process and handle large data sets, and consequently of interest or affordable only for a small number of professionals and institutions. This situation may radically change in the not-so-distant future as Future Internet technologies excel at processing unformatted, scarcely populated, and uncertain data sets. Such data is rare in the orderly world of the "old" Environmental Informatics but omnipresent today due to the Internet, the improved connectivity of electronic devices, and the increasing role of citizen-generated data for many emerging environmental applications.

These ongoing trends trigger changes in the environmental sector. Research undertaken by the authors indicated that (especially governmental) environmental organisations are facing the following data stewardship challenges:

- How are we to address the increasing societal expectations and legal requirements for data gathering, processing and dissemination with limited budgets (in public sector) and resources?

- How can societal expectations for data quality be met while supporting an increasing number of citizen observatories (Volunteered Geographic Information) and citizen science initiatives without jeopardising existing business models and reputations?

- How can we harness data with varying degrees of quality from diverse sources including citizen observatories and public government sources without compromising the quality of our own results?

At the abstract level, the answer to these challenges is clear: (1) sensor data gathering, quality assurance, and dissemination has to be optimized; (2) the business models of all stakeholders must be adopted to a situation where data is abundant and cheap; and (3) model developers must learn how to deal with auxiliary observations of low -and even unknown- data quality. At the technological level, one part of the solution is provided by the Future Internet technology.

To make the best use of both, geospatial and Future Internet technologies, we have to investigate new directions for designing and developing environmental software applications. While Big Data 
challenges still have to be addressed within the environmental domain (Hampton et al., 2013; Chen and Zhang, 2014), we have to provide holistic, flexible and scalable solutions that apply to a wide audience and ultimately enable multi-disciplinary research that is requested by initiatives such as the Global System Science ${ }^{1}$ and Future Earth ${ }^{2}$. It will be essential to cross the artificial boundaries between current sectors, interconnect already existing systems, and break technical as well as organisational barriers.

Anticipating these developments, Havlik at al. (2011) suggested a paradigm shift towards a datacentric Environmental Observation Web, where the output of processing and modelling services, as well as the data provided by humans and from hardware sensors are (almost) always modelled as observations. The Environmental Observation Web should account for semantically enriched content, modularized environmental simulations and content contributed by citizens. It shall enable the consumption, production and re-use of environmental observations in cross-domain applications. The design of a multi-style service-oriented-architecture was identified as a major challenge to facilitate existing generic Information and Communication Technology (ICT) solutions, enable robustness and scalability, and increase the interoperability between already existing systems (Usländer et al., 2010).

With this article, we present our experiences with the development of Fl-enabled Environmental Observation Web specifications, services and applications. We summarise the technical challenges for the construction of an Environmental Observation Web, including the access to crowd-sourced environmental observations, handling of heterogeneous data sources, and data processing at varying aggregation levels. Furthermore, we outline our development methodology together with the resulting architecture and service specifications. This work provides a crucial step in combining generic Future Internet technologies with functionality that is specific to earth and environmental sciences.

The remainder of this article is organised as follows: Section 2 introduces the key elements of the Future Internet processing paradigm, from the Environmental Informatics perspective. Section 3 outlines key characteristics of an Fl-enabled environmental architecture. Examples of environmental use cases and actual application prototypes illustrating the advantages of the proposed architecture are shown in Section 4. Finally, Section 5 presents the key outcomes of our work and identifies follow-up research activities.

\section{Relevant technologies and standards of the Future Internet}

In 2011, the European Commission (EC) initiated an ambitious 5-year "Future Internet - Public Private Partnership" (FI-PPP ${ }^{3}$ ) programme. The FI-PPP programme aims to deliver economic benefits from fast to ultra-fast Internet based interoperable applications (EC, 2011). The high-level objectives of the FI-PPP are: (1) to improve key Information and ICT infrastructures of Europe's economy and society; (2) to foster a European-scale Internet-enabled market and service economy; (3) to propel the creation and provision of Fl-enabled services and applications over and across domain sectors,

\footnotetext{
${ }^{1}$ http://global-systems-science.org

2 http://www.icsu.org/future-earth

${ }^{3}$ http://www.fi-ppp.eu
} 
businesses and stakeholders; and (4) to integrate and harmonize the relevant policy, legal and regulatory frameworks.

One of the main expected outcomes of the FI-PPP programme is the service-oriented analysis and design of an infrastructure comprising of reusable software components, so-called Generic Enablers (GEs) that can be used and combined in a flexible way for developing mash-up applications. GEs are general-purpose software components, i.e. implementations of services with open, standard interfaces, which can be reused in different domain sectors. According to the classification of Bieberstein et al (2006), GEs belong to the Component Layer of service-oriented analysis and design methodologies, which means that GEs encompass service engineering aspects. In this sense, they enable the design and engineering of smart applications based on Future Internet technologies. GE specifications and reference implementations are developed and promoted by the FI-WARE project ${ }^{4}$, while instances of GEs are deployed in the FI-WARE platform. All specifications and many of the reference implementations shall be freely available as open documentation/open source. For example, the FI-WARE Lab ${ }^{5}$ provides working instances of GEs to quickly develop and test enablerbased applications on top of the FI-WARE platform, and FI-WARE Accelerators ${ }^{6}$ are a promising way to ease networking and community engagement for developing FI-based applications targeted to specific domains. A variety of similar projects are harnessing the potentials of Cloud Computing and Big Data handling facilities to provide the next generation of data- and computing-intensive applications, such as the UK Environmental Virtual Observatory project (Vitolo et al., 2015), the US Earth Cube initiative ${ }^{7}$, and the Global Earth Observation System of Systems (GEOSS) ${ }^{8}$.

GEs in FI-WARE are structured along architectural groups or chapters (see Fig. 1): Cloud Hosting (data storage), Data/Context Management (Big Data processing and analytics), loT Services Enablement, Applications/Services Ecosystem Delivery Framework (registry, discovery and composition of services and applications), Security and Interface to Networks and Devices (security aspects and communication protocols). FI-WARE architectural chapters are highly independent from each other, and may heavily differ in terms of the standards, technologies, data models, data representations, and interaction patterns used. The variety of standards and preferred technology may be potentially seen as an integration issue. However, the specification of GEs relies strongly on open specifications and robust Application Programming Interfaces (APIs) ${ }^{9}$ that allow developers to access and integrate them easily. In addition, GEs are application- and use-case agnostic in the sense that no domainspecific semantics has been a priori taken into account for designing GEs. That is, GEs capture the commonalities of several application domains (e.g. environment, agriculture, energy).

\footnotetext{
${ }^{4}$ http://www.fi-ware.org

${ }^{5}$ http://lab.fi-ware.org

${ }^{6}$ http://www.fi-ware.org/accelerators

${ }^{7}$ http://www.nsf.gov/pubs/2013/nsf13529/nsf13529.htm

${ }^{8}$ http://www.earthobservations.org/geoss.shtml

${ }^{9}$ http://catalogue.fi-ware.eu
} 


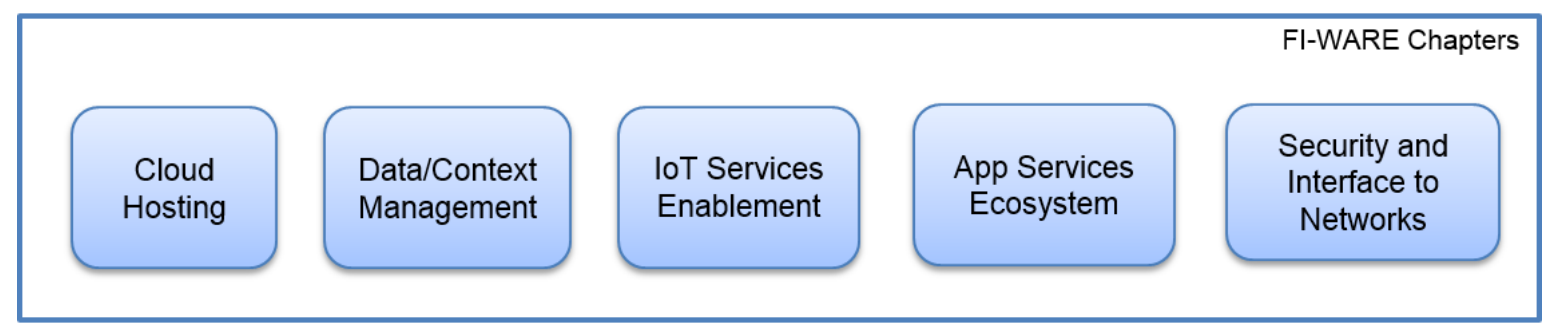

\section{Future Internet Technologies: Cloud Computing, Internet of Things, Big Data.}

Fig. 1: FI-WARE architectural chapters

The bottom-line idea is that GEs abstract Cloud Computing, loT low-level implementation details and Big Data handling capabilities through open specifications and APIs. In fact, GEs are particular instances of types of utility computing. For example, the Cloud Hosting chapter provides developers with GEs for data storage and management on cloud platforms; the Data/Context Management chapter introduces GEs for processing of event streams, performing map-reduce analysis of data and analysing unstructured data; and the loT Services Enablement chapter aims to make a large number of distributed and heterogeneous "things" available, searchable, accessible and usable. Users and developers can make use of these types of GEs in their applications and harness the potential of Future Internet technologies.

The environmental domain area was recognized as one of the central application domains within the FI-PPP programme ${ }^{10}$ framework of the EC. This domain was represented by the ENVIROFI project ${ }^{11}$. An analysis of the FI-WARE capabilities from the point of view of the environmental domain has been initially prepared in the scope of the project and its validity illustrated in various follow-up projects of the authors (see acknowledgments). In this section, we present key Future Internet technologies pertinent to Cloud Computing, loT, and Big Data, including the identified challenges and open issues for bringing Future Internet capabilities closer to geospatial and environmental services as well as applications. Where applicable, these findings were updated to reflect the authors' findings since the ENVIROFI project end in 2013.

\subsection{Cloud Computing}

Cloud Computing refers to computing as a service that meets essential needs and requirements of cross-domain applications (Buyya et al., 2009). Offered by cloud providers various types of computing services are available for stakeholders. This includes (i) software as a service (SaaS), where applications are delivered as services over the Internet (e.g. Google Maps), (ii) platforms as a service (PaaS), where cloud providers deliver an entire computing platform for developing and running applications (e.g. Google App Engine), and (iii) infrastructures as a service (laaS) that comprises the underlying hardware and system resources (e.g. data centres) needed to support PaaS and SaaS, such as Amazon EC2/S3. The key benefit of Cloud Computing is the provision of ready-to-use, scalable and

\footnotetext{
${ }^{10}$ http://www.fi-ppp.eu/

${ }^{11} \mathrm{http}: / /$ www.envirofi.eu
} 
on-demand services to a wide range of stakeholders who are oblivious to technical details and the underlying complexity.

Yang et al. $(2011 ; 2013)$ recently reviewed research results on Cloud Computing to address particular needs in geospatial and Digital Earth applications (Goodchild et al., 2012). The authors noted that the combination of service-oriented architecture(s) with cloud computing faces the challenges of storage and scalability in a global context, thereby reflecting the community's need to manage large-scale collections of observations and processed data from environmental models and data fusion services. Wen et al. (2013) implemented an open cloud-based environment to let users create, deploy and share their own cloud-based geographic analyses models.

In terms of synergies between Cloud Computing and environmental sciences, Sun (2013) described a step-by-step migration of a small-scale watershed management system from traditional client-server architecture to cloud-based services. Wang et al. (2013) explored remote sensing processing methods and strategies for large-scale meteorological monitoring in real-time and natural disaster warning scenarios. These authors concluded that the use of Cloud Computing is especially effective when the management of huge volumes of data and distributed parallel processing are essential requirements. Fustes et al. (2014) took advantage of cloud resources for data, and processingintensive marine applications, such as the detection and localization of marine spills by combining remote sensing methods with advanced segmentation algorithms within a cloud platform.

Nevertheless, several issues and technology challenges still require the realisation of computing as a utility service. Improvements on performance, security and privacy as well as quality of service are unavoidable requirements for future cloud-based developments (Buyya et al., 2009; Zhang et al., 2010; Moreno-Vozmediano et al., 2013). These concerns are addressed, e.g. by Srirama et al. (2012), who proposed to transform existing scientific computing algorithms into native algorithms that can successfully exploit the cloud platform's benefits. Buyya et al. (2009) highlighted the need for a marketplace that brings together cloud providers and consumers; allowing the registration, publication and discovery of cloud services. Sections 3 and 4 emphasize how Future Internet technology embraces the computing utility vision for environmental services and applications, through the design and implementation of Specific Enablers and services that seamlessly exploit Cloud Computing capabilities. By doing so, we aim to make environmental application development easier by fostering the reuse of cloud-based enablers, which aligns with the European Cloud Computing Strategy ${ }^{12}$ to promote the rapid adoption of Cloud Computing in all market sectors (including the space, geospatial and environmental sectors) to boost productivity and assure economic sustainability.

\subsection{Internet of Things}

The second relevant trend is the Internet of Things (IOT) phenomenon. loT covers a wide range of technologies and envisions a variety of "things" or objects, which are physically and/or virtually interrelated and are able to communicate with each other to deliver a new class of applications and services (Atzori et al., 2010). Because of the heterogeneity of the technology, the loT paradigm encompasses different visions with distinct enabling technologies. Atzori et al. (2010) give a networkcentric vision on the loT paradigm while focusing on communication technologies such as

${ }^{12}$ http://www.cloudforeurope.eu 
identification and tracking or wireless networks. The authors identified several open issues concerning networking aspects in the sense of enabling interoperability among diverse and heterogeneous devices. Miorandi et al. (2012) provided a recent update on technologies, applications and research challenges from a network-centric perspective.

In contrast to the network-centric vision described above, the loT paradigm favours a thing-centric perspective, in which services associated to things are central. These services manage large data streams captured by smart objects or things with the support of cloud infrastructure. Instead of being disjoint paradigms, one key aspect is the integration of loT with Cloud Computing in the form of SaaS-like value-added services (Miorandi et al., 2012; Gubbi et al., 2013). The ENVIROFI platform follows a thing-centric vision for using loT in geospatial and environmental applications. It provides a set of enablers (SaaS-like) that encapsulate loT low-level communication protocols to application developers through open specifications and APIs. In this way the rapid creation and deployment of loT-based environmental applications on cloud infrastructures is fostered.

Apart from the integration of Cloud Computing and loT, most studies perceive participatory sensing (also referred to as user-generated data and crowdsourcing), data fusion and data analytics as challenging capabilities to be integrated in the context of loT (Atzori et al., 2012). Undoubtedly, there is great value in engaging people in the collection of data to increase their awareness of environmental issues. This is limited by the lack of data fusion and modelling services that could intelligently integrate user-generated observations (e.g. from smart devices), measurements (e.g. from sensor stations), and reference data (e.g. from institutional data repositories) in a generic way. This much-needed capability will in principle provide reliable input to decision-making processes in the wider scope of environmental management such as water network monitoring and quality assurance of drinking water or monitoring of urban transport, air quality and traffic noise pollution. For instance, networks of people and smart objects could work collaboratively to sense and produce meaningful data for monitoring air quality in cities (Predic et al., 2013).

As far as the implementation of services is concerned, standards-based web service implementations are widely considered to support the development of flexible and dynamic services for environmental modelling applications (Granell et al., 2010; Goodall et al., 2011; Goodall et al., 2013; Castronova et al., 2013; Granell et al., 2013). The service abstraction can successfully enable readyto-use, on-demand services that utilize Cloud Computing and loT capabilities. The application of service-oriented architecture (SOA) principles represents a very powerful approach for creating environmental applications based on services that rely on Cloud Computing and loT paradigms. Nevertheless, it would still require suitable methods for discovering, deploying and composing services at run-time to support all stages of the application life cycle.

The Environmental Observation Web equally fits into the SOA and loT principles. For example, the Sensor Web Enablement (SWE) standard specifications of the Open Geospatial Consortium (OGC) enable the discovery of sensors and their observations, exchange and processing of such observations, as well as tasking of sensors and sensor network systems (Bröring et al., 2011). The predominant role of SWE standards in designing environmental software applications has been widely validated (Usländer et al., 2010; Hill et al, 2011; Chen et al., 2012; Díaz et al., 2013), together with mature implementations of SWE-based services in a wide range of environmental domain applications (OGC SWE report, 2013). Despite these advances, Havlik et al. (2011, p. 3876) posed the 
question whether "environmental applications do not use the decentralized and collaborative nature of today's Internet to its maximal extent. Consequently, the actual exploitation of environmental observations and systems lags behind the increasing demands for timely and contextually aware information delivery". Since the term "sensor", as defined in the OGC SWE observation and measurement model, is flexible enough to include any sort of observational data, physical devices and things, while being capable of maintaining standardized definitions for domain-specific parameters and variables, it became the data model of choice to collect, query, access, and publish observations in the domain of the Environmental Observation Web.

\subsection{Big Data}

Big Data immediately emerges when the notion of Environmental Observation Web, loT, and Cloud Computing are discussed. Even though several definitions of Big Data have been proposed over the past years, there is no agreed definition of Big Data yet. From the emerging literature (Laney, 2001; Dumbill, 2013; Mayer-Schönberger and Cukier, 2013; Kitchin, 2014), a number of characteristics are common to most definitions: Big Data is huge in volume, is created in near real-time (data streams being continuously generated and collected), diverse in variety (being structured and unstructured in nature), and exhaustive in scope (capturing entire populations or at least larger datasets).

For many, Big Data handling capabilities would open up an entirely new approach of doing science based on data-intensive analysis and discovery (Hey et al., 2009). Indeed many research efforts are now directed towards the development of enabling technologies or paradigms to support requirements for Big Data handling. New strategies for databases have been experimented with both, the so called NoSQL databases such as Google BigTables (Chang et al., 2006) and its successors (e.g. CouchDB ${ }^{13}$ ). One advantage is that they allow working with unstructured data, and array databases (Baumann and Holsten, 2012) designed for scientific applications where multi-dimensional structures are common. Specific solutions for Big Data analytics have been developed, based on mobile code such as in the European Grid Infrastructure $\left(E G I^{14}\right)$, the Earth System Grid Federation $\left(E G^{15}\right.$ ) infrastructure (Cinquini et al., 2014) and middleware (including FI-WARE GEs) through optimized SQL extensions such as in the FP7 EarthServer ${ }^{16}$ raster query language (Baumann et al., 2015) or through PaaS cloud solutions specifically tailored to Earth Science, such as Google Earth Engine $^{17}$. Nevertheless, compared to dedicated GIS-enabled relational databases, geospatial processing capabilities of current Big Data solutions, such as NoSQL databases, are still extremely limited (Yang et al., 2011; 2013).

While these solutions address mainly the volume and velocity axes, other architectural and technological solutions are aiming to address the variety of dimensions to handle heterogeneous datasets. Brokered architectures provide a valuable solution for efficiently connecting existing infrastructures (Nativi et al., 2013) and providing large amounts of heterogeneous resources to big System of Systems such as the Global Earth Observation System of Systems (GEOSS). Access to the collection of GEOSS datasets was made possible through the adoption of a brokered architecture

\footnotetext{
${ }^{13}$ http://couchdb.apache.org

${ }^{14}$ http://www.egi.eu

${ }^{15}$ http://esgf.org

16 http://earthserver.eu

17 http://earthengine.google.org
} 
composed of a set of components referred to as the GEO Discovery and Access Broker (GEO, 2012), which are based on the same FI technology adopted for some Specific Enablers (Section 3).

Environmental sciences are also embracing Big Data technology (Vitolo et al., 2015). Steed et al. (2013) described a visual analytics system, called the Exploratory Data analysis ENvironment (EDEN), for the analysis of complex Earth system simulation data sets. Hampton et al. (2013) encouraged ecologists to join in global initiatives to address scientific and societal problems by publishing their small data sets in big repositories in order to harness the power of collective Big Data. If such data is considered this valuable, surely equivalent benefits could be gained by collecting, sharing and integrating data generated at several scales by other communities including volunteering citizens (Scholes et al., 2012). Through crowdsourcing-oriented platforms and mobile technologies, citizens at different levels of technical expertise are empowered to collect, produce, and publish environmental that can be used by scientific communities. Participatory sensing and crowdsourcing demonstrate the value of sharing small and localized observations that, when aggregated in Big Data repositories, build a deeper and broader understanding of environmental phenomena.

Along the same lines Havlik et al. (2011) observed the importance of user communities in generating valuable environmental data. They noted, though, that 'these communities' environmental observations represent a wealth of information which is currently hardly used or used only in isolation and therefore in need for integration with other information sources. Only then, it will lead to a new paradigm shift from a mere Sensor Web to an Observation Web." (Havlik et al., 2011; p. 3874). The challenges of using citizen-generated data are similar to traditional data sharing and data integration challenges which are more generally present in Big Data analytics, service-oriented architectures and Cloud Computing (Granell, 2014). In the intersection of Big Data and crowdsourcing, the examples of Fl-enabled environmental applications in Section 4 make the case for combining user-generated, contextualised, and local data (e.g. user's location, objects around one's vicinity, etc.) captured by mobile applications along with large sensor observational data.

Future Internet technologies - Cloud Computing, loT, and Big Data handling - are gradually transforming the way environmental software applications are being developed, deployed and shared. These new approaches become even more necessary when multi-disciplinary teams are involved in the development of environmental applications. For example, the combination of weather and chemical models to estimate air quality and predict pollution exposures is currently not supported. The integration of climate change scenarios and ecosystems data to predict how biodiversity is affected (Nativi et al., 2009) requires ICT infrastructures and enabling technology to support such multi-disciplinary scenarios.

\section{Reusable Enablers for Environmental Applications}

In the scope of FI-PPP programme, we (the authors of this article) and the rest of the ENVIROFI team performed a thorough analysis of the requirements of the Environmental Observation Web. This analysis explored EU-wide and world-wide initiatives such as the Group of Earth Observations $\left(G_{E O}{ }^{18}\right)$, Shared Environmental Information Systems $\left(\mathrm{SEIS}^{19}\right)$, Infrastructure for Spatial Information in

\footnotetext{
18 http://www.earthobservations.org

${ }^{19}$ http://www.eea.europa.eu/about-us/what/shared-environmental-information-system-1
} 
the European Community (INSPIRE $\left.{ }^{20}, E C, 2007\right)$, and ongoing trends towards democratization of the Environment Informatics through citizens science and citizens observatories (Dickinson and Bonny, 2012; Roy et al., 2012; Science Communication Unit, 2013). In the next step, we mapped these requirements on the $\mathrm{Fl}$ capabilities, provided the environmental domain specific requirements to $\mathrm{FI}-$ WARE, and laid the foundation for the Fl-enabled Environmental Observation Web, in which environmental data from sensor observations, user-generated observations or phenomenological models are made available and accessible in a standardized format. The key elements of the resulting architecture are discussed hereafter.

\subsection{Architecture of the Environmental Applications}

Environmental information infrastructures are characterised by longevity, and in many cases large scale. For example, an in-situ monitoring system often covers very large areas, different Earth representations (coordinate reference systems, resolution, data models, etc.), and a typical life time of such systems is measured in decades. As new functionality is added, environmental infrastructures inevitably grow more and more heterogeneous over time. Addressing heterogeneity at every level (interfaces, metadata and data models, formats, coordinate reference systems, ontologies, etc.) is the main requirement for a data sharing system in the environmental and Earth science domain. Two general approaches are possible for addressing the heterogeneity issue: (i) standardisation that defines common specifications for interfaces, metadata and data models; and (ii) mediation that adapts and harmonises heterogeneous interfaces, metadata and data models.

Standardisation helps, but we cannot resolve the issues by standardisation alone. The provision and adoption of common specifications require that participating organizations are strongly committed in their adoption (e.g. for legal enforcement, or for strong interest due to clear and immediate benefits from data sharing), and that they have high ICT expertise, since specifications for large and heterogeneous domains are unavoidably complex. In the case of the environmental and Earth science domains, data providers and users generally have an interest in sharing data inside their own communities through dedicated infrastructures, without a specific commitment to participate in overarching data sharing initiatives. Moreover, the standardisation process is usually very slow compared to the rapid pace of ICT development. Consequently, the standardisation at the technology level is virtually impossible and the environmental information infrastructures will remain heterogeneous at the technology level in the foreseeable future (Bleier et al., 2009).

Mediation is possible if and only if the harmonisation and adaption of interfaces, metadata and data models is theoretically and practically feasible. First, this means that distinct data models must be correctly modelled and mapped to a higher-level conceptual model that can be used to reconcile the heterogeneous implementations. Second, the number of interfaces, metadata and data models must be kept as small as possible to efficiently develop and maintain the middleware mediators that bridge distinct components and systems. The standardisation and harmonisation of the data models is a pre-requisite for mediation and these two approaches are just two aspects of the overall architectural approach in which a single conceptual architecture can be mapped to multiple implementation architectures.

${ }^{20}$ http://inspire.ec.europa.eu 
The ENVIROFI approach brings standardisation and mediation to a new level where co-existence of different technologies within a single application is a rule rather than exception (ENVIROFI Consortium D4.2, 2012). On the standardisation side, we first set out a generic environmental monitoring and decision lifecycle process based upon the INSPIRE lifecycle service perspective (manage, observe, publish/discovery, compose/analyse), and we extended it with a step for acting and notification, i.e. making decisions to initiate actions and issuing notifications (Fig. 2). The exploration of the different steps (manage, observe, publish, etc.) helped us identify relevant interfaces, metadata and data models from standardisation bodies and consortia such as the International Organization for Standardization (ISO) and the OGC, and communities such as INSPIRE (EC, 2007) working groups and the Taxonomic Databases Working Group (TDWG) standards ${ }^{21}$. This exploratory activity provided us a set of specifications for modelling most of the observational data handled in the earth and environmental science domains.

The environmental monitoring and decision lifecycle served as a framework for the generalisation of use case functionality from the various environmental pilot applications (Fig. 3). For example, the identification of the main functions required for observing, discovery, publishing and so on. During this exercise, mediation played a crucial role because it allowed us to access existing infrastructures and mediate between different interfaces, metadata and data models published, building a so-called system of systems in a brokered or mediation approach to conveniently exploit resources from existing infrastructure and platforms, as the case of the GEs deployed in the FI-WARE platform. The resulting combination of architectural approaches contributed to standardisation activities under CEN/TC289 TR 15449 on Spatial Data Infrastructure (CEN/TC289, 2011; CEN/TC289, 2012), and ISO/TC211 19119 Geospatial Services (ISO 19119, 2013).

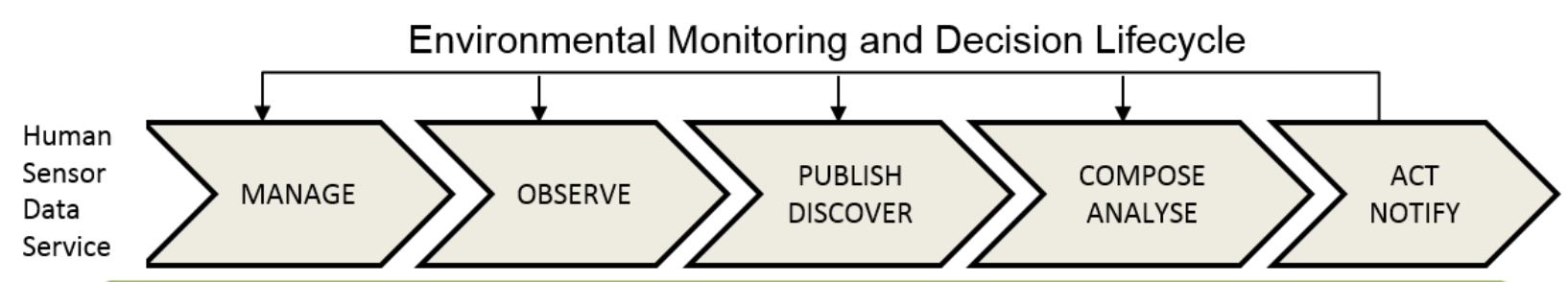

Environmental (Biodiversity, Atmospheric and Marine) Applications

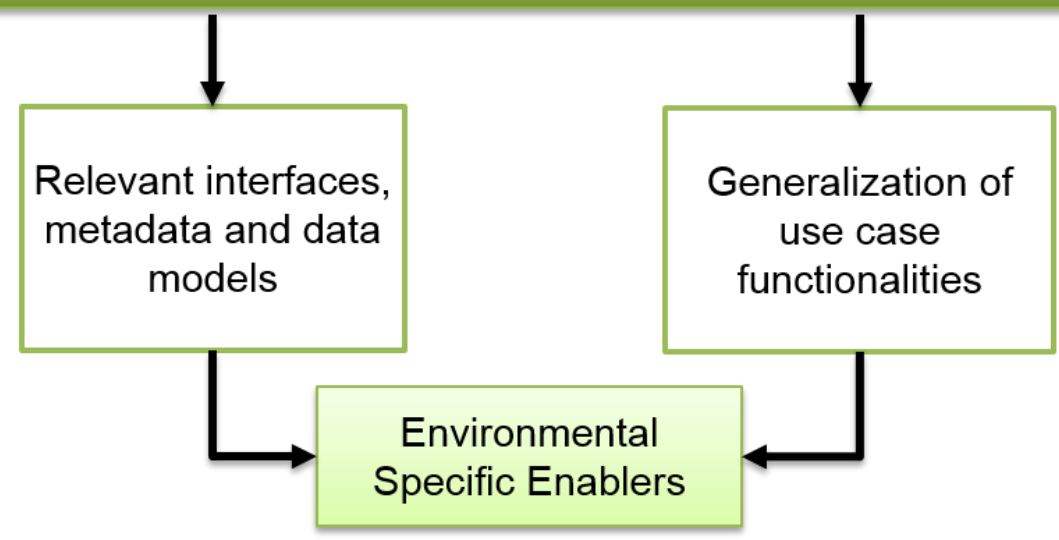

Fig 2: ENVIROFI approach to the identification of Specific Enablers according to the environmental monitoring and decision lifecycle

\footnotetext{
${ }^{21}$ TDWG is part of the Biodiversity Information Standards (http://www.tdwg.org) and should not be confused with the in Thematic Domain Working Groups of INSPIRE.
} 


\subsection{Enabler-centric view}

Since the main part of the work presented here was performed within the scope of the FI-PPP programme, we decided to use the FI-PPP naming scheme for "Enablers" throughout the article. In a broader sense, enablers are either network-enabled software components featuring open, standard interfaces, which can be re-used and combined in a flexible way, or cyber-physical systems linking such software components with a specific hardware. Conceptually, they smoothly encapsulate and enable the use and combination of Cloud Computing, loT, and Big Data handling for developing software applications in different domain sectors. From a functional perspective, such a commonly agreed and re-usable set of enablers is a welcome contribution to environmental system-of-systems that may drastically cut down the development and maintenance costs of environmental applications as well as improve interoperability.

Generic Enablers introduced in Section 2 are general-purpose software components which can be reused in different domain sectors. Per analogy, the Specific Enablers (SEs) are reusable and commonly shared functional building blocks which are specific for a certain domain. All SEs described in this work are pertinent to the environmental and geospatial fields. The establishment of links and synergies between GEs and SEs is vital to the realization of enabler-based environmental applications. Following the FI-WARE example, the environmental SEs are also broken into thematic groups or chapters based on the type of functionality and role they provide in the realm of environmental applications.

\subsection{Design and implementation of Environmental Specific Enablers}

The classification of SEs emerged from the combination of different forces. We first captured specific requirements from the three ENVIROFI pilot applications thorough a proven analysis methodology (accompanied by other requirements from wider initiatives such as Copernicus, INSPIRE, GEOSS and continuous consultation activities (e.g. surveys, meetings, workshops ${ }^{22}$ ) with interested stakeholders over the course of the project. Combined with this, the environmental monitoring and decision lifecycle framework in Section 3.1 was crucial to identify key functionality and standards, data models and service interfaces specifications used in the environmental and geospatial domains.

By combining these different techniques, we identified the list of potential SEs and clustered them into functionally similar groups or chapters illustrated in Fig 3 . This allowed us to identify overlapping functionality offered by the GEs and SEs at design time and to focus on really new SEs for environmental applications.

\footnotetext{
${ }^{22}$ For example, the ENVIROFI Day conference held in Dublin on March 2013, http://www.eurescom.eu/newsand-events/eurescommessage/eurescom-messge-1-2013/environmental-observation-and-the-future-internetenvirofi-day-in-dublin.html.
} 


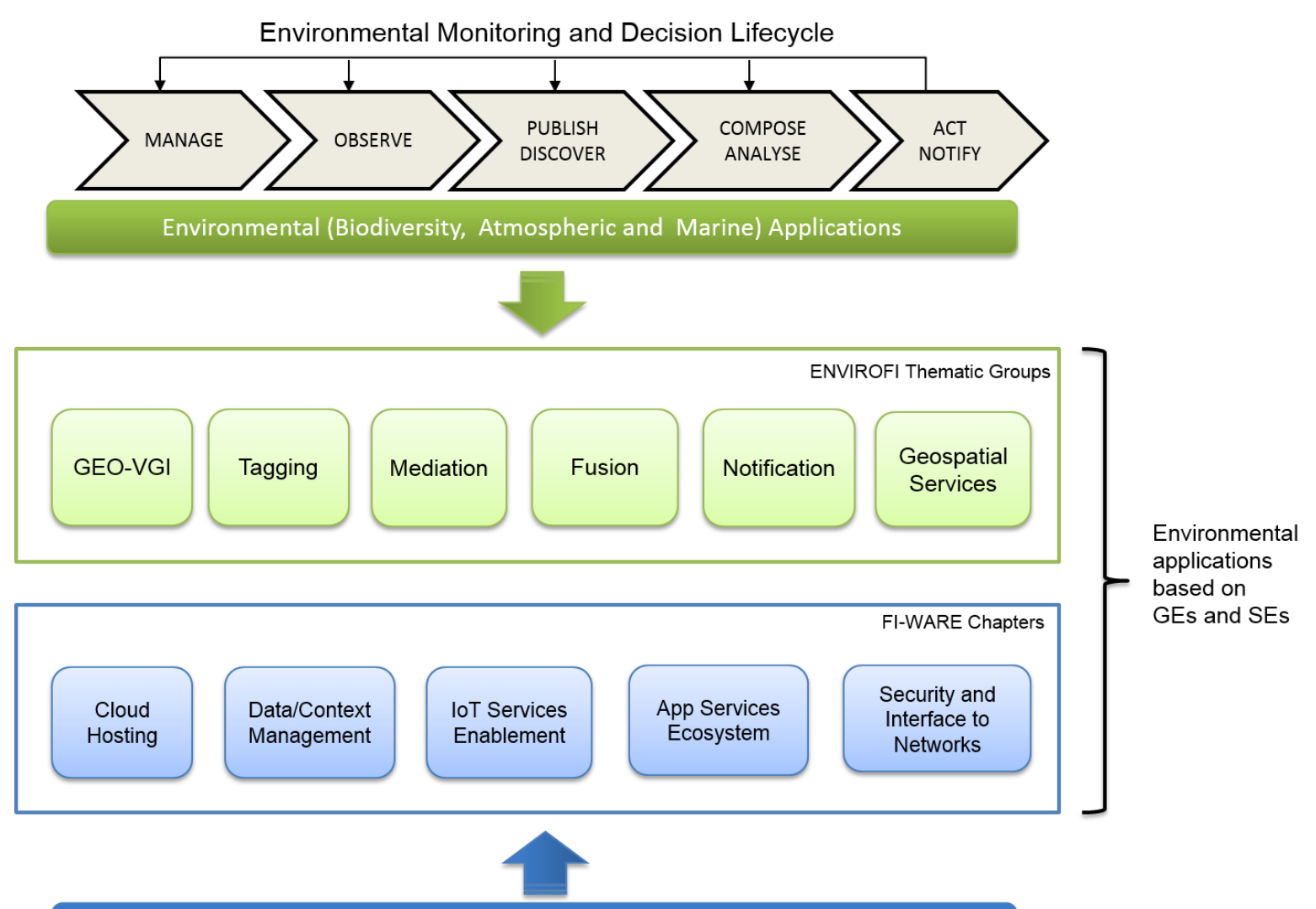

Future Internet Technologies: Cloud Computing, Internet of Things, Big Data.

Fig. 3: Environmental application development is based on the pool of SEs and GEs which abstract environmental specific functionalities and cross-domain functionalities respectively

The six thematic groups or architectural chapters that classify SEs are: GEO-VGI (geo-referenced data collection applications and crowd-sourcing), Tagging (semantic tagging tools), Mediation (mediators, harvesters and mediators), Fusion (fusion tools for heterogeneous data sources), Notification (event detection and notification), and Geospatial Services. In subsequent development, we identified the software which already implements much of the required functionality and focused our work accordingly:

- SEs related to event detection and notification (Notification) and semantic tagging tools (Tagging) were awarded own architectural chapters because such functionalities are commonly found in many environmental applications. Our later experiences with counterpart GEs have shown that most of the functionality of the environmental SEs pertinent to these chapters can be adequately substituted by more generic Future Internet solutions, although a domain-specific "profiles" will be needed at least at the level of the data model and in some cases at the level of geo-enablement. For example, event subscription based on geographic area is badly missing in the Pub/Sub GE specifications (within the Data/Context management chapter), but adding such functionality to generic event handling GEs would probably requires less effort than maintaining a separate set of geospatial notification services. 
- In addition, the Geospatial Services thematic group introduces the SEs for provisioning and storage of environmental observations and measurements. These SEs are based on wellknown OGC service specifications (e.g. WMS, WFS, and WPS). Since multiple commercial and open source implementations of related specification already exist, they were re-used without changes.

- Finally, the Mediation (mediators, harvesters and mediators) thematic group introduces a collection of brokers, connectors and mediator services which support protocols and data models found in the environmental domain. Although a similar functionality is foreseen within the FI-WARE architecture, the mediation between GEs, SEs and the existing environmental services and Spatial Data Infrastructures has to be implemented by the environmental and geospatial ICT community. The mediation group also includes wellestablished services such as ERDDAP ${ }^{23}$ and GI-* (GI star) Discovery and Access brokering suite ${ }^{24}$, which can be used "as is" or with modest adaptation efforts in different environmental applications.

Consequently, most of the development effort within the ENVIROFI project has been invested in the following two thematic groups.

GEO-VGI (geo-referenced data collection applications and crowd-sourcing) refers to SEs which provide ways to record and archive environmental geo-referenced measurements for later use by other SEs such as fusion services. Typically, these SEs are used together to realize mobile Volunteered Geographic Information (VGI) applications which combine local situation awareness, crowdsourcing of the observations (participatory sensing), and crowd-tasking to provide additional information and to assess the quality of the already provided observations (Havlik et al., 2013b). The set of SEs facilitates integration of data and processing capabilities realised by third party services and provides a way to push alerts and task requests to selected users. In particular these SEs share a common data model similar to the standardized OGC Observation \& Measurements (O\&M, ISO 19156, 2011) data model, but the service access interface is RESTful and the input and output data is encoded in GeoJSON rather than in XML. The feasibility of encoding observations in O\&M and accessing them over OGC Sensor Observation Service (SOS), as well as the interaction with the event processing and dispatching GEs have been demonstrated (Havlik et al., 2013a). Indeed, the versatility and flexibility of OGC standards based specifications and data models are seen as a way to ease working with large, heterogeneous amounts of data as they integrate metadata information and standard definitions of domain-specific variables and uncertainties (Vitolo et al., 2015).

Fusion (fusion tools for heterogeneous data sources) includes a wide range of enablers to cover functionality as diverse as pre-processing, feature extraction, situation assessment, modelling and prediction services, preparing, and aggregating environmental data into formats suitable for use by human end users and automated services such as alert services.

Considering the size and diversity of the environmental and geospatial informatics sectors, the list of 20+ SEs which have been designed, developed and satisfactorily tested in the project represents only a tip of the iceberg. Nevertheless, the lessons learned are really interesting: all but the core services

\footnotetext{
${ }^{23}$ Environmental Research Division's Data Access Program, http://erddap.marine.ie/erddap/index.html.

${ }^{24}$ GI-cat, http://essi-lab.eu/do/view/GIcat/WebHome; GI-axe, http://essi-lab.eu/do/view/Glaxe/WebHome.
} 
supporting the geospatial data manipulation and processes and the specialised data fusion and modelling services, can be adequately implemented by using GEs - either "as is" or with minimal changes. In other words, it is reasonable to expect that the Fl technology stack will soon provide a backbone for a great majority of new environmental applications. More information on individual SEs and on the ways these SEs can be used in applications can be found on the ENVIROFI Catalogue ${ }^{25}$.

\section{Examples of Future Internet enabled Environmental Applications}

This section presents some concrete examples of environmental applications and application prototypes which (can) profit from the use of Future Internet technologies - including, but not limited to the concrete FI-WARE GEs. Section 4.1 includes a detailed analysis of the roles of individual GEs and SEs in the "Biodiversity" application prototype (Schleidt et al., 2013). Other application examples in Section 4.2 are presented at a higher level of abstraction, without going into the details of the implementation architecture.

\subsection{Biodiversity application}

\subsubsection{ENVIROFI-BIO functional description}

The Biodiversity application prototype (ENVIROFI-BIO) ${ }^{26}$ was designed to allow users with varying degrees of knowledge about biodiversity to both receive and provide data in a simple interactive manner, through a smartphone app. The app targeted the amateurs interested in discovering and tracking the biodiversity in their neighbourhood, as well as the professionals interested in the long term monitoring. The species list was limited to trees, because initial tree lists for the test locations were easily available and because the number of involved species was considered irrelevant for the purpose of technology testing. It has been tested on three scenarios at different scale:

- The Vienna Trees app cover the Vienna city and utilizes the data (e.g. tree cadastres) provided under the city of Vienna's Open Government Data ${ }^{27}$.

- The Citizens in Tuscany app uses Open Data from the city of Florence ${ }^{28}$ to cover rural areas in the Tuscany region.

- Finally, the usability for scientists was tested in the Long Term Ecological Research (LTER) site Zöbelboden ${ }^{29}$, where various attributes pertaining to trees are regularly monitored over a long time period.

Users can obtain information in interesting tree species and biodiversity habitat in a specific region with respect to their current location or a different location they are considering visiting. This allows users for example to examine locations of tree species and habitat occurrence records and to view detailed information about observations on them. The queried data can be filtered based on the user's interests, and displayed either in tabular form or using interactive maps (Fig. 4a).

\footnotetext{
${ }^{25}$ http://catalogue.envirofi.eu

${ }^{26}$ The ENVIROFI-BIO app is currently a working prototype on the Android platform. For further information and download, please refer to the ENVIROFI catalogue available at http://catalogue.envirofi.eu.

${ }^{27}$ https://open.wien.at

${ }^{28} \mathrm{http}: / /$ opendata.comune.fi.it

${ }^{29} \mathrm{http}: / /$ www.umweltbundesamt.at/en/services/services pollutants/services airquality/en ref zoebelboden
} 
The ENVIROFI-BIO app allows for the collection and provision of crowd-sourced biodiversity data, which can be a valuable supplement to official data from scientific repositories and open data sources. Users can either upload a new tree occurrence record taken in a location or create new observations on existing tree occurrence records (Fig. 4b). Collected observations can be cached offline for later synchronisation in areas with no network coverage. Environmental situation awareness is improved through provision of additional observations and feedback on existing data, making the available data more robust.

In order for this crowd-sourced biodiversity data to be useful, various quality assurance mechanisms must be in place (Bonter and Cooper, 2013). One approach for assuring the quality of observation data is a context-aware approach. The ENVIROFI-BIO app informs on the exact location of the user at the time of reporting an observation, as well as the time at which the observation was first reported. By comparing user-contributed data with existing data sources such as known species distributions, a plausibility of the reported species existing in the area can be calculated.

Species distribution information is only available for certain species, is not always completely reliable, and is prone to change due to additional factors such as human pressures and climate change. Additional spatial mechanisms were used for estimating the plausibility of a biodiversity occurrence record. In particular, we utilized a third-party, external web service called eHabitat (Dubois et al., 2013) that allowed us to assess the likelihood of finding equivalent ecological habitats, considering a wide range of variables that characterize these habitats. The eHabitat ecological modelling service let us determine the plausibility that a tree species occurrence could occur in the region reported by comparing it against the habitat and distribution of species known.

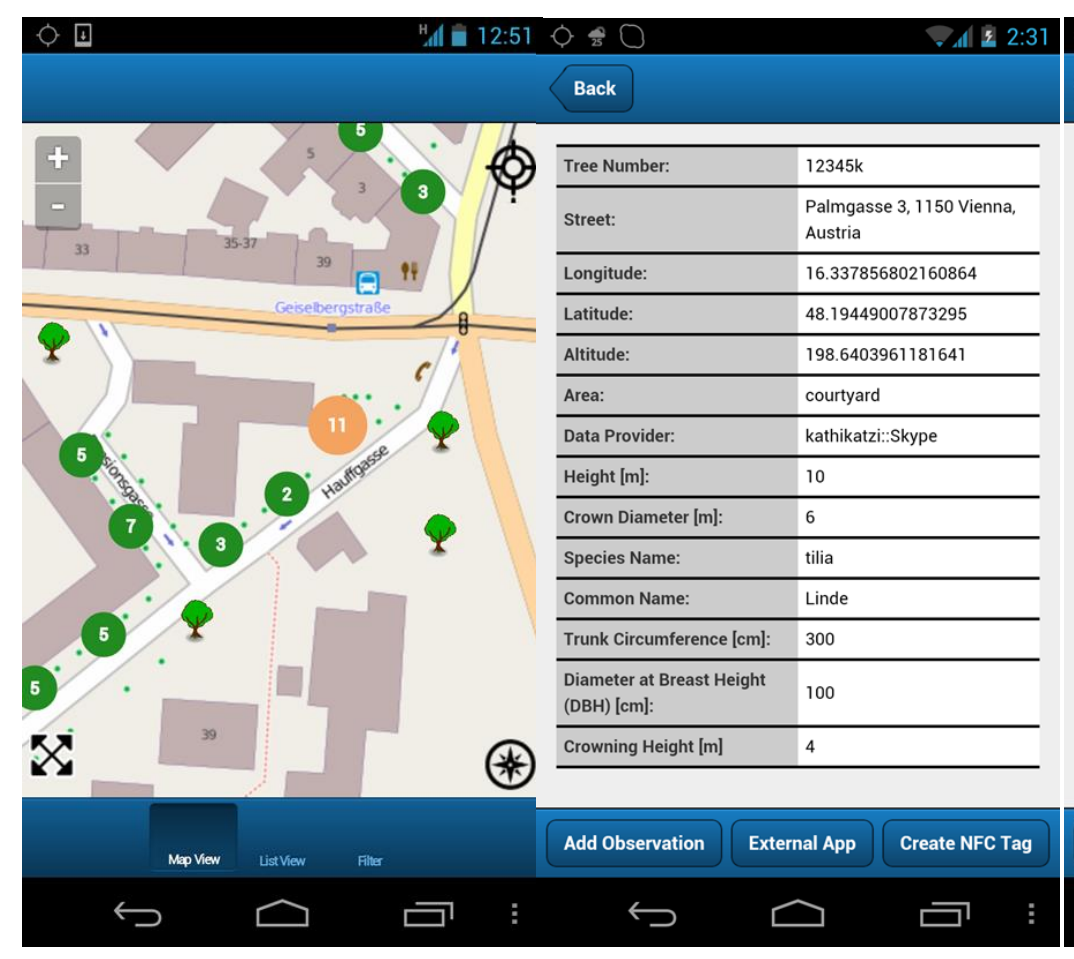

(a)

(b)

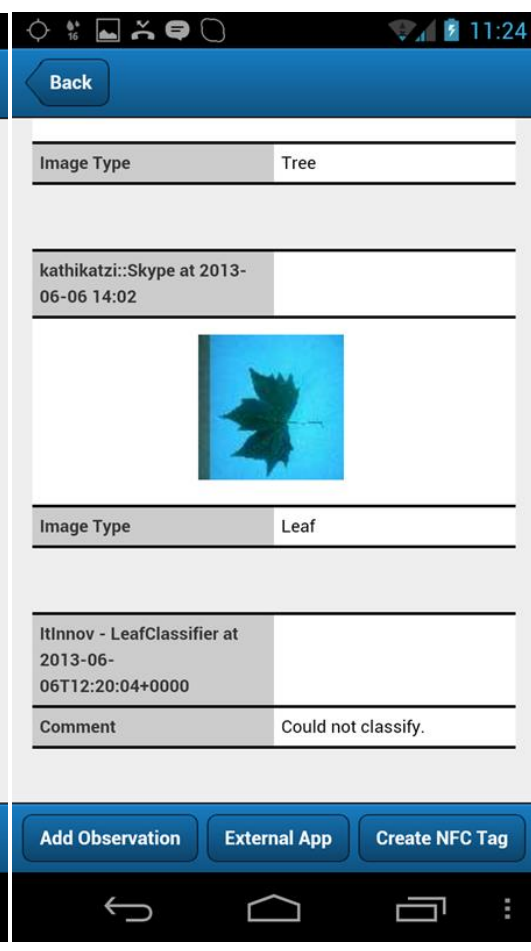

(c)

Fig. 4. Screenshots of the ENVIROFI-BIO app. (a) Objects of interest (trees) displayed in a map-based interface around user's location; (b) Details of an object of interest, a tree, and the Add Observation button) to insert a user observation about it; (c) Details of a user observation as an leaf image. 
A recurring problem in biodiversity data is the inaccuracy of species naming. This is due mainly to changes in the taxonomy, ambiguity in common names, and difficulties in properly spelling Latin names. To circumvent this, all species identifications (currently available in German and Italian language since the app was tested in Vienna and Florence) reference a species ontology called $\mathrm{TaxMeOn}^{30}$. When the user starts typing a name the app automatically provides species names from this ontology. The ontology entry selected provides the final species identification (See Species Name field in Fig. 4b).

\subsubsection{ENVIROFI-BIO implementation architecture}

The Biodiversity pilot is the most complex ENVIROFI application in terms of the number of involved Specific and Generic Enablers. The GEs, SEs and third-party, external components and services involved in the biodiversity application are shown in Fig. 5.

As explained earlier, the ENVIROFI-BIO app has been tested on three different locations to gain wider scale coverage. Each sub-pilot combined a core set of enablers (orange and purple boxes) with local services and open data servers (light blue boxes). For example, initial occurrence data for the first two use cases was provided by open data servers of Vienna and Florence. LTER data was imported from a file previously generated from the Monitoring and Research Information System (MORIS) database (Schentz et al., 2005). Base maps for visualization purposes were provided by external services such as OGC WMS, OGC WFS and the Tile Map Service, which is used by Open Street Map $\left(\mathrm{OSM}^{31}\right)$ through Open Layers JavaScript client-side library. Additional background information was provided by the biodiversity ontology service and by Google's elevation service ${ }^{32}$. These thee examples demonstrate the potential to reuse SEs in a generic way to build customized, enabledbased environmental applications at different scale.

To guarantee reusability of the data collected, the data models used were based on ISO standards from the ISO 191XX series of spatial data standards. The data models were slightly modified to allow for easy communication with mobile devices, but were kept aligned so that later conversion to the explicit ISO models is possible (Schleidt et al., 2013). Data surveyed by this app could be reused in other contexts such as INSPIRE (EC, 2007).

In terms of SEs (orange boxes) the central functionality is provided by the three GEO-VGI enablers:

- The Georeferenced Observation App SE (mobile app) provides users with a possibility to view existing observations and report new species occurrences and observations on these objects of interest. It facilitates the quality assurance process by highlighting new observations which need to be validated by the users;

- The Georeferenced Observation Collection Service SE (backed server) combines the observations provided by users with those provided by external data sources and other SEs, and coordinates the work of all other GEs, SEs and external services involved in this application; and

\footnotetext{
${ }^{30} \mathrm{http}: / / \mathrm{www}$. Idf.fi/schema/taxmeon/index.html

${ }^{31}$ http://www.openstreetmap.org

${ }^{32}$ https://developers.google.com/maps/documentation/elevation/?hl=en
} 
- The Georeferenced Observation Proxy SE assures the mobile application can be used in offline mode.

In addition to the plausibility check offered by the eHabitat service, the Environmental Image Sample Classification Service SE performs automatic identification based on images of leaves, as the leaf illustrated in Fig. 4c. This SE analyses the shape and coloration of a leaf image and returns a ranked list of possible species identifications. Combined with the eHabitat modelling service, which assesses the probability of the reported species occurrence in the local habitat, it demonstrates two techniques which can be jointly used for the automated quality assessment of observations.

In terms of GEs (purple boxes) the following GEs were integrated in the biodiversity pilot application:

- The Identity Management GE for user authentication and authorisation;

- The Pub/Sub Broker for exchanging of events (observations) between the Georeferenced Observation Proxy SE and the Georeferenced Observation App SE (mobile client application); and

- The Cloud Storage GE for storing and accessing large binary objects (images of trees).

In addition, we developed a proof-of-concept web mashup application to facilitate user-driven quality assurance of Biodiversity data. This application was realised using the Wirecloud GE- a webbased, graphical mashup tool to assemble web services and enablers - to demonstrate the feasibility and usability of combining GEs and SEs to quickly prototype operational environmental applications (Havlik et al., 2013a).

\subsubsection{ENVIROFI-BIO the way ahead}

ENVIROFI-BIO app represents a very popular class of crowdtasking or mobile VGI applications where mobile participants are provided with local situation awareness and asked to perform some simple tasks and contribute their own observations (Havlik et al., 2013b). Similar applications have been designed and deployed, for instance, to monitor citizens mobility patterns, fight illegal dumps, map street networks, and optimize traffic routing (Usländer et al., 2013; Havlik et al., 2014). The strength of designing this type of applications with the Future Internet technology stack can be summarized with three words: flexibility, reusability and market.

The ENVIROFI-BIO application prototype could be easily extended to support other environmental markets such as generic plant and animal tracking, monitor seasonal changes or invasive species. Possible applications in the biodiversity domain include for instance: educational applications where pupils are urged to discover certain species within a limited time frame and report their findings (a variant of the geocaching game); forestry and agriculture applications where users track the spread of invasive species, pests and infections; and administrative applications where a state of the inventory and need for actions in response to user input in the form of "this tree is about to fall" are managed with the help of a mobile app. 


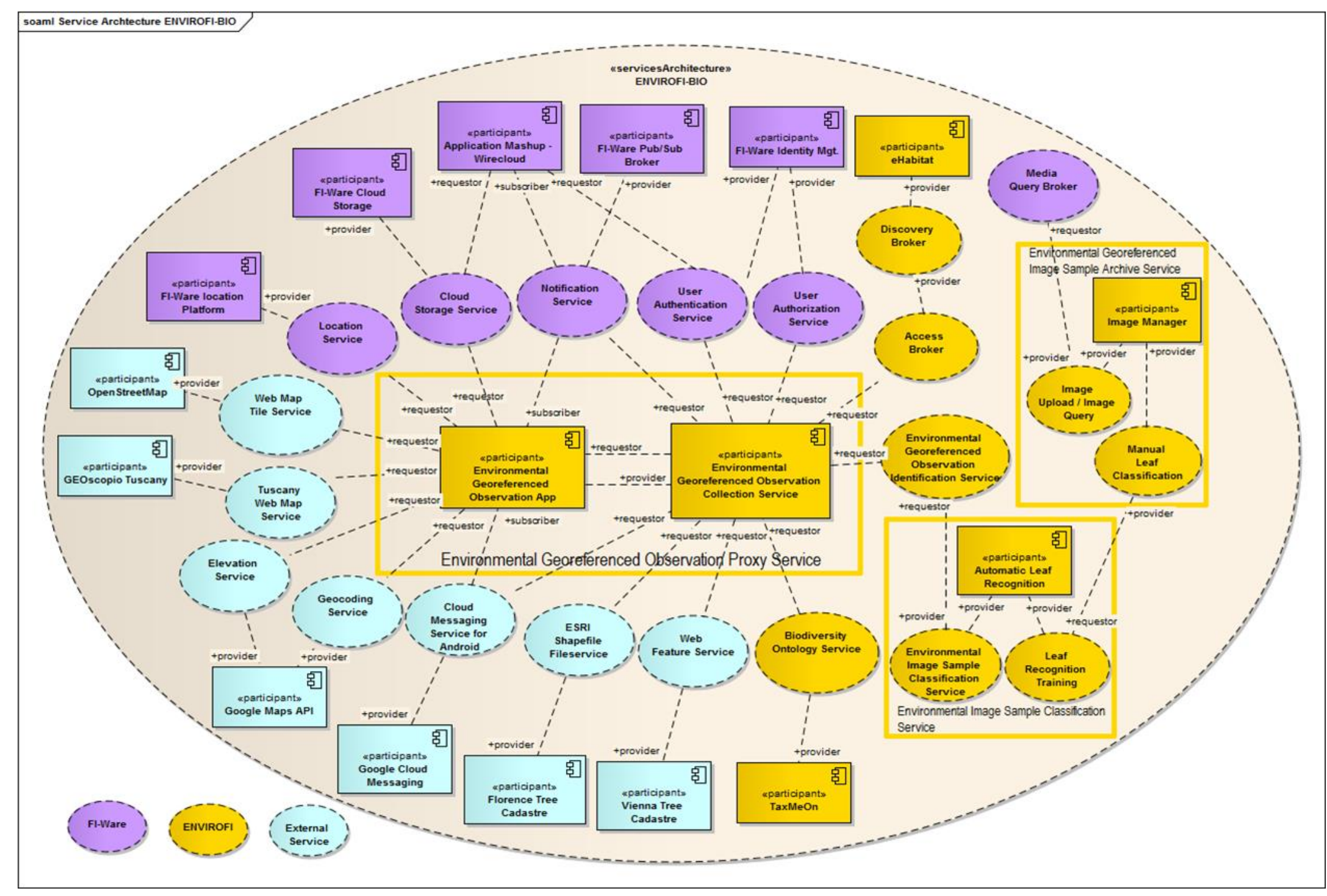

Fig. 5. Enabler-centric architecture view of ENVIROFI-BIO pilot application 
The importance of the FI technology at the level of flexibility and reusability can be illustrated by means of three SEs related to geo-referenced observations:

- The Georeferenced Observation Collection Service SE implementation has been built on top of the CouchDB NoSQL database to allow more flexibility, compared to SQL based databases, at the level of a (changing) data model. This required some re-education of our developers, and we switched to CouchOne for improved scalability and support after the project end. The takeaway message was clear: NoSQL is a way to go for flexible crowdtasking/VGI applications that need to manage increasingly larger and more complex data sets.

- The Georeferenced Observation App SE has been implemented as a hybrid application where almost all of the code is written in JavaScript/HTML5, to avoid vendor lock at the level of the smartphone operating system. This proved to be a bigger asset than initially expected later on, as we realised that the same functionality can be re-used both on the Web (e.g. to realize the Wirecloud widgets and mashup applications) and even embedded in the existing applications (Dihé et al., 2013).

- Finally, the Georeferenced Observation Proxy SE accounted for geo-aware data or file synchronisation, which should, in our opinion, be part of the generic Future Internet enablers stack. Rather than fully implementing such SE from scratch, a proof of concept was realised using the existing multi-master synchronisation capability of the CouchDB/CouchOne.

As confirmed by our experiences with the development of the Personal Environmental Information System (PEIS ${ }^{33}$ ) application (Kobernus et al., 2012b) in the ENVIROFI project, and more recently with the development of the crowd tasking application for coordinating the work of ad-hoc volunteers in crisis situations (Sebald et al., 2014) and awareness rising in relation to matters of air quality (Lahoz, 2013), the functionality provided by these SEs is required in virtually all crowdtasking/VGI applications. Similar functionality could, in principle, be realised in a more conservative way using the combination of SQL, native GUI application, and application-specific caching. The use of the Future Internet technologies has resulted in a faster and more agile development in spite of the issues we encountered due to own inexperience with the new technology stack (Kobernus et al., 2012). Similar considerations apply to the GEs used in the application. From the developers' point of view, the possibility to use GEs in own environmental applications without needing to develop, maintain or even install them on own servers is very convenient and - to a certain level - offsets the lack of the support for geospatial data in FI-WARE ${ }^{34}$.

Another very interesting aspect of the Future Internet technologies is the marketplace. In short, a marketplace is a specialised software catalogue which provides a simple way for a service or software owner to reach potential customers. Best known marketplaces are the ones for end users for Android and IOS apps, but the impact of a flourishing business to business (B2B) marketplace where

\footnotetext{
${ }^{33}$ For further information and access to PEIS, please refer to the ENVIROFI catalogue available at http://catalogue.envirofi.eu/applications/personal-environmental-information-system.

${ }^{34}$ We firmly believe that some basic geospatial operations, most notably the "find objects within a bounding box" will soon be included in (at least) the event-processing and data-access GEs.
} 
environmental data and services would be immediately visible and easily used by all potential customers on environmental informatics sector could be enormous.

Which brings us to environmental modelling and data fusion (and more generally data processing) SEs. In a previous section, we mentioned several SES of this type which were mainly used to improve the quality of user-contributed data. No matter how the ICT sector develops in the future, many data centric applications will need environmental modelling, data fusion, and data processing tasks, for example to assess and predict the state of the environment and to take into account the human/environment interactions. Depending on the algorithms, data and processing needs, some of the processing SEs will conveniently fit in a single virtual machine on a cloud, other will be able to profit from the horizontal scaling capability of the cloud, and some will still require a dedicated supercomputer to minimise the latency between the nodes. In all three cases, the owners of such services are likely to profit from higher visibility of their offerings which can be achieved through FI-enabling applications in terms of SaaS and marketplace.

\subsection{Marine Asset Management Decision Support Tool}

The Marine Asset Management Decision Support Tool (MAST) ${ }^{35}$ is a web portal that specialises in the analysis of marine assets use cases which were developed in the project. The use cases were mainly focussed on Ocean Energy Asset Management, which aimed to advance maritime situational awareness in Galway Bay, Ireland. This is specifically achieved through reliably interpreting offshore ocean energy arrays related MeteoOcean observations into meaningful information for offshore operations and management. Offshore operations span from enabling cost effective maintenance of ocean energy structures at opportunistic time windows to identifying the best investment areas for the development of ocean energy generation arrays in the future.

In this scenario, enabling mechanisms for data integration, sharing and distribution become central. As similar EU initiatives such as the Blue Growth ${ }^{36}$ policy and the Marine Spatial Planning and the Marine Strategic Framework Directive ${ }^{37}$ underline, a key asset of MAST is the availability of marine Open Data via distributed data networks and Web APIs that act as message brokering and data mediators. This approach has a number of advantages for the marine observation community and marine science:

- Big Data (i.e. data from forecast models) is kept close to the producer and the moving of voluminous data representing geospatially-distributed fields over networks is minimised;

- On the distributed network when data is kept at source then updates to the data propagate quicker. For example if a National Ocean Data Centre is a node on the network the data from the centre is more likely to be up-to date;

\footnotetext{
${ }^{35}$ For further information and access to MAST tool, please refer to the ENVIROFI catalogue at http://catalogue.envirofi.eu/applications/future-internet-collaborative-usage-of-marine-environmental-assets

${ }^{36}$ http://ec.europa.eu/maritimeaffairs/policy/blue growth

${ }^{37}$ http://ec.europa.eu/maritimeaffairs/policy/maritime spatial planning/index en.htm
} 
- Message brokering provides a single, consistent Web API to interact with several marine open data repositories; and

- Data mediation converts data from the sophisticated formats of Earth science to more familiar formats of the software development community, thus removing a technical barrier that had prevented the easy access to the marine science open data.

Figure 6 illustrates what can be achieved through marine open data repositories together with the distributed data network/brokering paradigm. The dashboard-like web portal displays live and forecast information for various physical environment parameters that are useful in determining the maritime situational awareness in Galway, Ireland. The data for the dashboard is supplied via sophisticated brokering, data fusion, and mediation enablers and made it available via Web APIs.

\section{ENVIR2FI}

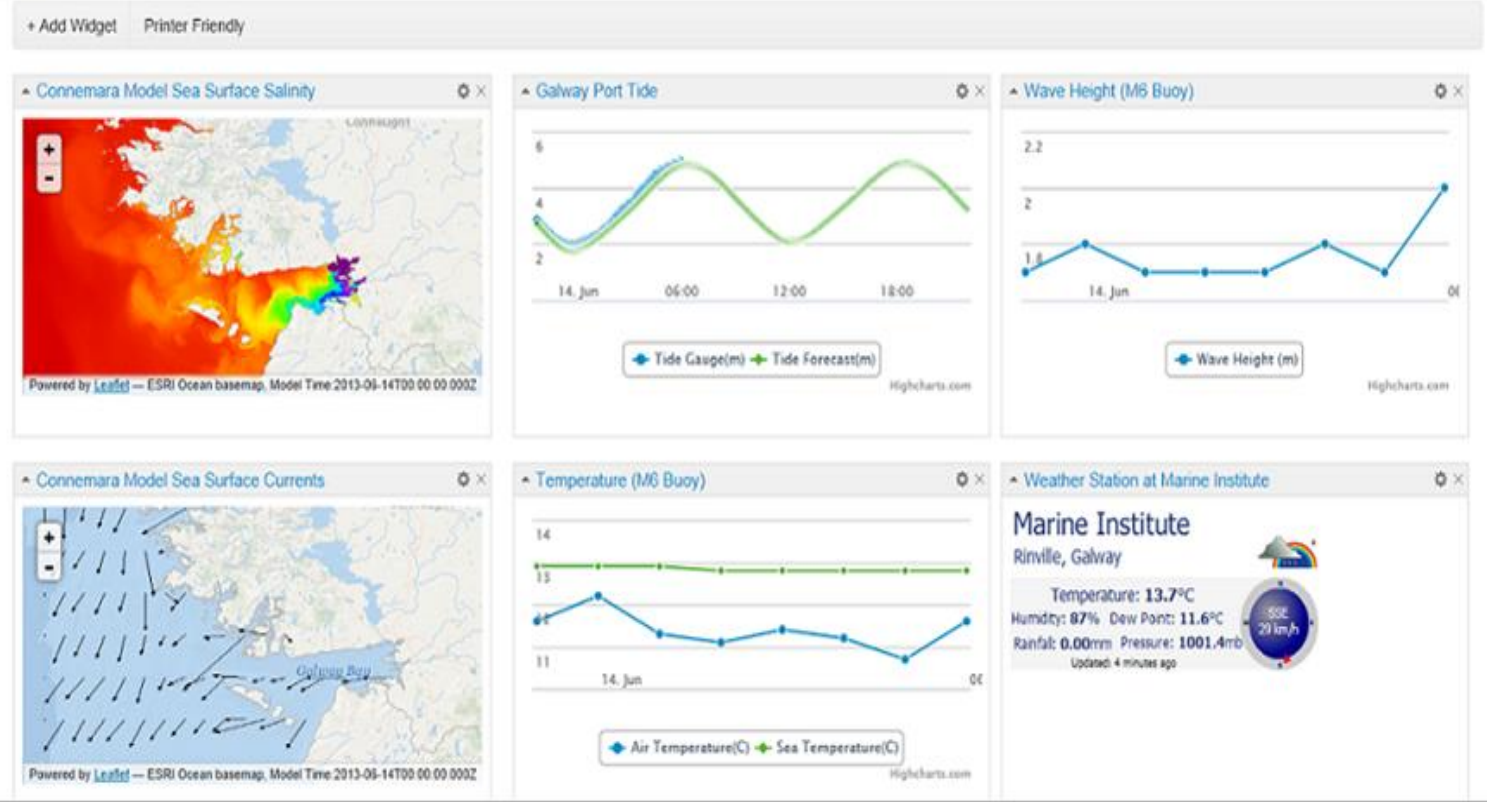

Fig. 6. Monitoring MeteoOcean conditions through MAST ${ }^{38}$

It was possible to enhance data integration in the context of the MAST dashboard by fusing the outputs from various marine sensors and ocean models with other data sources. Data fusion and modelling enablers were crucial to assimilate in the marine pilot application. Two remarkable SEs for data fusion and modelling activities are worth mentioning. The Spatial Temporal Data Fusion SE returned KML files of fused sea surface temperatures from various sources such as in-situ and satellite observation data from weather buoy sensors in the Irish Seas. It implemented the OGC SPS interface to offer a standards based API. To complement it, the Download and Transcode Sensor Data SE allows to access and download data from different environmental data sources, and turns it into an OGC compatible data model.

${ }^{38}$ http://apps.marine.ie/galwaydashboard 
The provisioning and sharing of marine situational awareness services was achieved through the use of a message brokering/data mediation SE called ERDDAP. It aimed to access the predicted weather and sea state data stemmed from ocean models through the earlier data fusion SEs. The ERDAPP SEs acts as a broker and provides observation data and valuable information (e.g. weather, and tidal conditions) from sensor networks and model forecasts (ocean and tide models). Resulting data can be made available through a number of channels such as the pan-European infrastructure for ocean and marine data management (SeaDataNet ${ }^{39}$ ).

ERDDAP SE can serve data through different interfaces such as WMS, SOS and JSON ${ }^{40}$. The presentation and visualisation of such data sets to the end user is made though several configurable widgets in the form of a dashboard web application (Fig. 6). The GUI for the dashboard was developed using JavaScript/HTML5. Again, the Identity Management GE may be used to handle the authentication and authorisation rules for the users to access to the MAST tool.

\section{Conclusion and recommendations for future work}

Our work on how Future Internet (through FI-WARE and ENVIROFI) supports the development of environmental applications has shown positive trends, but also highlighted some unresolved challenges. These are particularly for Earth Sciences and the development of environmental applications. In this section, we summarise our findings, discuss open issues and conclude with future recommendations.

\subsection{Key findings}

We perceive the Future Internet movement as a fruitful and promising opportunity to align the development of environmental applications with mainstream ICT solutions. Many of the GEs from FIWARE Cloud Hosting, Data/Context management and the Security chapters are suitable for filling the (standardisation) gaps in the environmental domain area. Based on our own experience, the integration of the Future Internet enablers (i.e. GEs and SEs) in environmental ICT can substantially lower the development and exploitation costs of future environmental applications. The examples described in this paper demonstrate that the FI-WARE platform and its GEs are not only well versed for developing applications in a wide range of domains and sectors, but that they are well suited to enhance existing technologies.

ENVIROFI SEs presented in this paper should be seen as a proof-of-concept demonstrating the feasibility and usability of using the FI-WARE technology in the environmental context. They significantly improve the inter-connection of environmental data with mainstream ICT, while at the same time presenting the applicability of generic and specific enablers in various environmental domains and across sectors. Many of the ENVIROFI services and enablers have also outlived the project and are used in various ways today. Some of the SEs, such as the Discovery Broker and the ERDDAP Access Broker and Mediator were already mature in 2013. The successful evaluation of ERDDAP in the ENVIROFI project led to its adoption by the

\footnotetext{
${ }^{39}$ http://www.seadatanet.org

${ }^{40}$ http://www.json.org
} 
Maritime Affairs Unit of the EC-JRC in order to access global weather and ocean forecast data ${ }^{41}$. In the USA, NOAA recommended the ERDDAP technology to be used by the National Weather Service for the hosting of operational geospatial data ${ }^{42}$.

Other ENVIROFI enablers and technologies have been developed further through individual efforts of the ENVIROFI partners in other EU projects and initiatives. Most notably, the data web services providing ambient air quality information in Norway have been incorporated into several EU projects such as e.g. the EU FP7 project CITI-SENSE (Lahoz, 2013). These web services supply background data to the project and can be used as a benchmark to compare micro sensors that are being deployed in Oslo. Further, the predictive air quality modelling service (three day air quality modelling) that NILU developed as a support service for the PEIS application is being used to inform Oslo citizens about future air quality in their neighbourhoods. Additionally, the Wirecloud mashup platform and the Pub/Sub Context Broker were re-used by AIT in the CRISMA project alongside standard OGC services. These helped achieve the functionality and maturity of results well beyond our initial expectations (Havlik et al., 2015).

Furthermore, GEO-VGI enablers' backend service has been further developed as the open source project "Ubicity" ${ }^{43}$ by the AIT (Pielorz et al., 2015). The concept of crowdtasking and the GEO-VGI front-end have been further extended and enhanced in cooperation with the Austrian Red Cross (Sebald et al., 2014). The resulting methodology with the concept of a crowdtasking service for crisis management is scheduled for testing by first responder organisations in the EU and Israel during 2016.

\subsection{Challenges}

It is important to understand that FI-WARE does not offer a full replacement of the existing environmental information systems, due to its less strong support for geospatial data and processing. However, the GEs from FI-WARE might offer stronger support for building environmental applications if the FI-WARE Platform was complemented with SEs on geospatial data technology. For example, the lack of spatial-temporal event processing is likely to hinder the uptake of the, otherwise very usable, FI-WARE event processing GEs in the environmental domain area. This issue cannot be fully addressed without extending this current GE to further functionalities for spatial-temporal event processing. Likewise, the FI-WARE Platform does not support standardised geospatial analysis, prediction and modelling functions within the existing GEs for data management and processing. Even though some geospatial processing capability is provided by the GEs in the loT chapter, their specifications overlap to some extent with those defined by a dedicated OGC Sensor Web interface for loT working group ${ }^{44}$ as part of the OGC's Sensor Web Enablement initiative.

This lack of coherent support for spatial-temporal processing is a major shortcoming of the current Future Internet solutions (van der Zee and Scholten, 2013; UN-GGIM, 2013; ITU, 2013), particularly since

\footnotetext{
${ }^{41}$ https://bluehub.jrc.ec.europa.eu/erddap/index.html

42 pers com with Jeff de La Beaujardiere, NOAA Data Management Architect and Acting Director, Technology, Planning \& Integration for Observations

43 http://ubicity.ait.ac.at:8080/portal/\#/

${ }^{44}$ http://www.opengeospatial.org/projects/groups/sweiotswg
} 
geospatial data technologies are cross-cutting through several application domains. They must consequently be considered among the core building blocks of the computing utility vision for the Future Internet. While the recent introduction of GIS-related GE (e.g. GIS Data Provider GE) is very welcomed, application developers are still hindered by the lack of support for geospatial data and processing when using other GEs. Thus, the important task of GIS-enabling the Future Internet really remains in the hands of the environmental and geospatial ICT sector.

\subsection{Recommendations}

Critical voices may question the real value and impact of FI-WARE outside the uptake of the EC-funded projects such as ENVIROFI. However, recent strategic actions might improve this situation in the immediate future. The Open \& Agile Smart Cities (OASC) initiative ${ }^{45}$ aims at combining the FI-WARE GEs APIs with the CitySDK ${ }^{46}$ data models. In this way, cities are encouraged to adopt open standard APIs and data models developed by the CitySDK project. In this context, fifteen large European cities are investigating the adoption of the FI-WARE platform in order to create and develop Smart City solutions which combines APIs that FI-WARE GEs provide with cities offered data. The definitive uptake of the FIWARE platform by the global market remains an open issue, but the strategic step to position FI-WARE as the envisioned Smart City Platform, where environmental and geospatial applications play a dominant role, deserves a much closer look.

The adoption of the Fl business and application models can help us leverage the unused potential of open data stemming e.g. from citizens' observatories and public cloud facilities. In our opinion, the uptake of new business models to exploit the next-generation of services and applications is a must for today's environmental sector ${ }^{47}$. The Future Internet provides answers to fundamental challenges as described in section 1 , such as societal expectations and legal requirements towards open government data, impacts on business models and data quality guarantees. In fact, the "FI way to go" that is indicated by the success of Big Data analytics, has been already anticipated by the environmental informatics community for a while: (1) by publishing your own data for public re-use; and (2) by improving your applications through the inclusion of all available and relevant open data. The fundamental and important change in the Future Internet which has recently occurred is the paradigm shift towards agile development, widespread re-use of data for different purposes, encouragement of machine to machine interoperability and data brokers, and the fusion of heterogeneous data as a common rule rather than an exception.

\section{Acknowledgments}

The work presented in this paper has been partially funded by the EC under the Seventh Framework Programme (FP7/2007-2013) as the ENVIROFI research project, Grant agreement $n^{\circ} 284898$ (ENVIROFI:

\footnotetext{
${ }^{45}$ http://www.oascities.org/open-agile-smart-cities/

46 http://www.citysdk.eu/

${ }^{47}$ The European App Economy, http://www.visionmobile.com/product/the-european-app-economy
} 
The Environmental Observation Web and its Service Applications within the Future Internet). The authors would like to thank the FI-WARE project team for their collaboration and technical support.

\section{References}

Atzori, L., lera, A., Morabito, G., 2010. The Internet of Things: A survey. Computer Networks 54(15), 2787-2805.

Atzori, L., lera, A., Morabito, G., Nitti, N., 2012. The Social Internet of Things (SloT) - When social networks meet the Internet of Things: Concept, architecture and network characterization. Computer Networks 56(16), 3594-3608.

Baumann, P., Holsten, S., 2012. A Comparative Analysis of Array Models for Databases. International Journal of Database Theory and Application 5(1), 89-120.

Baumann, P. et al., 2015. Big Data Analytics for Earth Sciences: The EarthServer Approach. International Journal of Digital Earth. DOI: 10.1080/17538947.2014.1003106

Bieberstein, N., Bose, S., Fiammante, M., Jones, K. and Shah, R., 2006. Service-Oriented Architecture (SOA) Compass - Business Value, Planning and Enter-prise Roadmap. IBM Press developerWorks Series. ISBN 0-13-187002-5, 2006.

Bleier, T. et al., 2009. SANY: an open service architecture for sensor networks. SANY Consortium. http://eprints.soton.ac.uk/id/eprint/355932.

Bonter, D.N., Cooper, C.B., 2012. Data validation in citizen science: a case study from Project FeederWatch. Frontiers in Ecology and the Environment 10, 305-307.

Bröring, A., Echterhoff, J., Jirka, S., Simonis, I., Everding, T., Stasch, C., Liang, S., Lemmens, R., 2011. New Generation Sensor Web Enablement. Sensors 11, 2652-2699.

Buyya, R., Yeo, C.S., Venugopal, S., Broberg, J., Brandic, I., 2009. Cloud computing and emerging IT platforms: Vision, hype, and reality for delivering computing as the 5th utility. Future Generation Computer Systems 25(6), 599-616.

Budhathoki, N.R., Bruce, B., Nedovic-Budic, Z., 2008. Reconceptualizing the role of the user of spatial data infrastructure. GeoJournal: An International Journal on Geography 72, 149-160.

Castronova, A.M., Goodall, J.L., Mostafa M. Elag, M.M., 2013. Models as web services using the Open Geospatial Consortium (OGC) Web Processing Service (WPS) standard. Environmental Modelling \& Software 41, 72-83.

CEN/TC289, 2011. CEN/TC289 - TR 15449 Geographic information - Spatial Data Infrastructures - part 1 Reference model, November 2011. 
CEN/TC289, 2012. CEN/TC289 - TR 15449 Geographic information - Spatial Data Infrastructures - part 4, Service Centric view, May 2012.

Chang, F., Dean, J., Ghemawat, S., Hsieh, W. C., Wallach, D. A., Burrows, M., Chandra, T., Fikes, A., Gruber, R. E., 2006. Bigtable: A Distributed Storage System for Structured Data. Google Research Publications. Available at http://research.google.com/archive/bigtable-osdi06.pdf.

Chen, N., Hu, C., Chen, Y., Wang, C., Gong, J., 2012. Using SensorML to construct a geoprocessing eScience workflow model under a sensor web environment. Computers \& Geosciences 47, 119-129.

Chen, C., Zhang, C.-Y., 2014. Data-intensive applications, challenges, techniques and technologies: A survey on Big Data. Information Sciences 275, 314-347.

Chesbrough, H.W., 2003. Open Innovation: The New Imperative for Creating and Profiting from Technology. Boston: Harvard Business School Press.

Cinquini, L., Crichton, D., Mattmann, C., Harney, J., Shipman, G., Wang, F., Ananthakrishnan, R., Miller, N., Denvil, S., Morgan, M., Pobre, Z., Bell, G.M., Doutriaux, C., Drach, R., Williams, D., Kershaw, P., Pascoe, S., Gonzalez, E., Fiore, S., Schweitzer, R., 2014. The Earth System Grid Federation: An open infrastructure for access to distributed geospatial data. Future Generation Computer Systems 36, 400-417.

Díaz, L., Bröring, A., McInerney, D., Libertá, G., Foerster, T., 2013. Publishing sensor observations into Geospatial Information Infrastructures: A use case in fire danger assessment. Environmental Modelling \& Software 48, 65-80.

Dickinson, J.L., Bonney, R., 2012. Citizen Science: Public Participation in Environmental Research. Comstock Publishing Associates.

Dihé, P., R. Denzer, M. Polese, A. M. Heikkilä, D. Havlik, J. Sautter, Th Hell, S. Schlobinski, G. Zuccaro, and W. Engelbach. "An architecture for integrated crisis management simulation." In Proceedings of the 20th International Congress on Modelling and Simulation, Adelaide, Australia, pp. 1-6. 2013.

Douglas, L. 2001. 3d data management: Controlling data volume, velocity and variety. Gartner.

Dubois, G., Schulz, M., Skøien, J., Bastin, L., Peedell, S., 2013. eHabitat, a multi-purpose Web Processing Service for ecological modeling. Environmental Modelling \& Software 41, 123-133.

Dumbill, E., 2013. Making sense of Big Data. Big Data 1(1), 1-2.

ENVIROFI Consortium D4.1.2, 2012. D4.1.2 Environmental Requirements II, available at: http://cordis.europa.eu/fp7/ict/netinnovation/deliverables/envirofi/deliverables-envirofi en.html

ENVIROFI Consortium D4.2, 2012. D4.2 Environmental Architecture, available at: http://cordis.europa.eu/fp7/ict/netinnovation/deliverables/envirofi/deliverables-envirofi en.html

ENVIROFI Consortium D4.4, 2013. D4.4 Final Recommendations for Environmental Enablers, available at: http://cordis.europa.eu/fp7/ict/netinnovation/deliverables/envirofi/deliverables-envirofi en.html 
ENVIROFI Consortium D5.5, 2013. "D5.5 Online documentation for conceptual prototypes", available at: http://cordis.europa.eu/fp7/ict/netinnovation/deliverables/envirofi/deliverables-envirofi en.html

ENVIROFI Consortium D5.6, 2013. D5.6 Validation report.

EC, 2007. Directive 2007/2/EC of the European Parliament and of the Council of 14 March 2007 establishing an Infrastructure for Spatial Information in the European Community (INSPIRE). Official Journal of the European Union 108, 25.4.2007, p. 1-14.

EC, 2010a. EUROPE 2020 - A Strategy for Smart, Sustainable and Inclusive Growth; European Commission: Brussels, Belgium, 2010.

EC, 2010b. Europe 2020 Flagship Initiative Innovation Union; Communication; European Commission: Brussels, Belgium, 2010.

EC, 2010c. A Digital Agenda for Europe; Communication; European Commission: Brussels, Belgium, 2010.

EC, 2011. Future Internet Public Private Partnership; European Commission: Brussels, Belgium, 2011.

Fernando, N., Loke, S.W., Rahayu, W., 2013. Mobile cloud computing: A survey. Future Generation Computer Systems 29(1), 84-106.

Fustes, D., Cantorna, D., Dafonte, C., Arcay, B., Iglesias, A., Manteiga, M., 2014. A cloud-integrated web platform for marine monitoring using GIS and remote sensing. Application to oil spill detection through SAR images. Future Generation Computer Systems 34, 155-160.

GEO, 2012. GEO 2012-2015 Work Plan Implementation Report - Task Assessment - Document 6 - As accepted at GEO-IX. Available at:

http://www.earthobservations.org/documents/geo ix/06 GEO\%2020122015\%20Work\%20Plan\%20Implementation\%20Report Task\%20Assessment.pdf

Gubbi, J., Buyya, R., Marusic, S., Palaniswami, M., 2013. Internet of Things (IoT): A vision, architectural elements, and future directions. Future Generation Computer Systems 29(7), 1645-1660.

Goodall, J.L., Robinson, B.F., Castronova, A.M., 2011. Modeling water resource systems using a serviceoriented computing paradigm. Environmental Modelling \& Software 26(5), 573-582.

Goodall, J.L., Saint, K.D., Ercan, M.B., Briley, L.J., Murphy, S., You, H., DeLuca, C., Rood, R.B., 2013. Coupling climate and hydrological models: Interoperability through Web Services. Environmental Modelling \& Software 46, 250-259.

Goodchild, M.F., Guo, H., Annoni, A., Bian, L., de Bie, K., Campbell, F., Craglia, M., Ehlers, M., van Genderen, J., Jackson, D., Lewis, A.J., Pesaresi, M., Remetey-Fülöpp, G., Simpson, R., Skidmore, A., Wang, C., Woodgate, P., 2012. Next-generation Digital Earth. Proceedings of the National Academy of Sciences 109(28), 11088-11094. 
Granell, C., Díaz, L., Gould, M., 2010. Service-oriented applications for environmental models: reusable geospatial services. Environmental Modelling \& Software 25(2), 182-198.

Granell, C., Schade, S., Ostländer, N., 2013. Seeing the forest through the trees: A review of integrated environmental modelling tools. Computers, Environment and Urban Systems 41, 136-150.

Granell, C., 2014. Robust Workflow Systems + Flexible Geoprocessing Services = Geo-enabled Model Web? In E. Pourabbas (Ed): Geographical Information Systems: Trends and Technologies. Boca Raton: CRC Press, pp. 172-204.

Hampton, S.H., Strasser, C.A., Tewksbury, J.J., Gram, W.K., Budden, A.E., Batcheller, A.L., Duke, C.S., Porter, J.H., 2013. Big data and the future of ecology. Frontiers in Ecology and the Environment 11, 156162.

Havlik, D., Schade, S., Sabeur, Z.A., Mazzetti, P., Watson, K., Berre, A.J., Mon, J.L., 2011. From Sensor to Observation Web with Environmental Enablers in the Future Internet. Sensors 11(4), 3874-3907.

Havlik, D., Soriano, J., Granell, C., Middleton, S.E., van der Schaaf, H., Berre, A., Pielorz, J., 2013a. Future Internet enablers for VGI applications. Proceedings of the 27th Conference on Environmental Informatics (Envirolnfo 2013), Hamburg, Germany. Shaker Verlag, Aachen, pp. 622-630.

Havlik, D., Egly, M., Huber, H., Kutschera, P., Falgenhauer, M., Cizek, M., 2013b. Robust and Trusted Crowd-Sourcing and Crowd-Tasking in the Future Internet. In J. Hrebícek, G. Schimak, M. Kubásek, A.E. Rizzoli (Eds): Environmental Software Systems. Fostering Information Sharing (10th IFIP WG 5.11 International Symposium on Environmental Software Systems, ISESS 2013), Neusiedl am See, Austria, October 2013. Springer, vol. 413, pp. 164-176.

Havlik, D. and Schimak, G., 2014. State and trends in mobile observation applications. In D. P. Ames, N. W. T. Quinn and A. E. Rizzoli (Eds.): 7th Intl. Congress on Environmental Modelling and Software, San Diego, CA, USA, http://www.iemss.org/sites/iemss2014/papers/iemss2014 submission 388.pdf

Havlik, D., Dihé, P., Frings, S., Steinnocher, K., Aubrecht, C. (eds.), 2015. Catalogue of CRISMA decision support applications, framework building block specifications and software implementations. CRISMA consortium, Available at https://crisma-cat.ait.ac.at/content/crisma-catalogue-book

Hill, D.J., Liu, Y., Marini, L., Kooper, R., Rodriguez, A., Futrelle, J., Minsker, B.S., Myers, J., McLaren, T., 2011. A virtual sensor system for user-generated, real-time environmental data products. Environmental Modelling \& Software 26(12), 1710-1724.

International Council for Science (ICSU), 2010. Grand Challenges in Global Sustainability Research: A Systems Approach to Research Priorities for the Decade. International Council for Science: Paris, France, 2010.

ISO 19156, 2011. ISO 19156 Geographic information - Observations and measurements, 2011. Also OGC Standard Abstract Specification, http://www.opengeospatial.org/standards/om 
ISO 19119, 2013. ISO/TC211 - ISO 19119 PT/EC revision draft, May 2013.

ISO/IEC 10746-1, 1998. Information technology -- Open Distributed Processing -- Reference model: Overview.

International Telecommunication Union (ITU), 2013. ITU Technology Watch Report on Location matters: Spatial standards for the Internet of Things, September 2013. http://www.itu.int/dms pub/itut/oth/23/01/T23010000210001PDFE.pdf

Kitchin, R., 2014. The real-time city? Big data and smart urbanism. GeoJournal: An International Journal on Geography 79, 1-14.

Kobernus, M., Schade, S., Havlik, D., Egly, M., Pielorz, J., Denby, B., 2012. Agile applications - a new paradigm, an old devil. In Proceedings of 8th International Air Quality Conference 2012, Athens, Greece.

Kobernus, M., Havlik, D., Van der Schaaf, H., Pielorz, J., Falgenhauer, M., 2012b. A quest for affordable personalized atmospheric exposure estimates. Envirolnfo Dessau 2012, Part 1: Core Application Areas, Shaker Verlag Aachen, ISBN: 978-3-8440-1248-4.

Lahoz, W., 2013. CITIZENS' OBSERVATORY - Where does our air quality come from? Meteorological International August 2013:126-128. http://www.citi-

sense.eu/LinkClick.aspx?fileticket=t7R\%2f7mgGYDU\%3d\&tabid=11064\&mid=17225

Laney, D., 2001. 3D Data Management. Controlling Data Volume, Velocity, and Variety in Application Delivery Strategy, META Group, February 2001.

Hey, T., Tansey, S., Tolle, K. (edited by), 2009. The Fourth Paradigm - Data-Intensive Scientific Discovery. Microsoft Research, 2009. Available at: http://research.microsoft.com/en-

us/collaboration/fourthparadigm/4th paradigm book complete Ir.pdf

Mayer-Schönberger, V., Cukier, K., 2013. Big Data: A revolution that will transform how we live, works and think. London: John Murray.

Miorandi, D., Sicari, S., De Pellegrini, F. Chlamtac, I., 2012. Internet of things: Vision, applications and research challenges. Ad Hoc Networks 10(7), 1497-1516.

Moreno-Vozmediano, R., Montero, R.S., Llorente, I.M., 2013. Key Challenges in Cloud Computing: Enabling the Future Internet of Services. IEEE Internet Computing 17(4), 18-25.

Nativi, S., Craglia, M., PearIman, J., 2013. Earth Science Infrastructures Interoperability: The Brokering Approach. IEEE Journal of Selected Topics in Applied Earth Observations and Remote Sensing 6(3), 11181129.

Nativi, S., Mazzetti, P., Saarenmaa, H., Kerr J., Tuama E. Ó., 2009. Biodiversity and climate change use scenarios framework for the GEOSS interoperability pilot process. Ecological Informatics 4(1), 23-33. 
OGC SWE Report, 2013. Implementation Maturity Engineering Report, https://portal.opengeospatial.org/files/?artifact id $=53823$

Pielorz, J., Ruggenthaler, C., Huber, H., Nowak, A., 2015. Ubicity - Conquering Crisis and Disaster Management Challenges with Big Data Analytics. Proceedings of the $10^{\text {th }}$ Future Security, to appear.

Predic, B., Yany, Z., Eberlez, J., Stojanovic, D., Abererz, K., 2013. ExposureSense: Integrating Daily Activities with Air Quality using Mobile Participatory Sensing. In Proceedings of PerCom Demos 2013, San Diego, pp. 303-305.

Roy, H.E., Pocock, M.J.O., Preston, C.D., Roy, D.B., Savage, J., Tweddle, J.C., Robinson, L.D., 2012. Understanding Citizen Science \& Environmental Monitoring. Final Report on behalf of UK-EOF. NERC Centre for Ecology \& Hydrology and Natural History Museum. Available at: http://www.ceh.ac.uk/products/publications/documents/citizensciencereview.pdf

Schentz, H., Schleidt, K., König, M., Mirtl, M., 2005. MORIS - MEDEA or using ecological tools for Monitoring or Meteorological Extreme Events. In: Hrebicek, J. \& Racek, J. (Eds.) Informatics for Environmental Protection. Networking Environmental Information. Proceedings of the ENVIROINFO Brno 2005. Brno, Czech Republic. pp. 365-370.

Schleidt, K., Laurenne, N., Giacomelli, A., Havlik, D., 2013. ENVIROFI - Bringing Biodiversity to the Future Internet. In J. Hrebícek, G. Schimak, M. Kubásek, A.E. Rizzoli (Eds): Environmental Software Systems. Fostering Information Sharing (10th IFIP WG 5.11 International Symposium on Environmental Software Systems, ISESS 2013), Neusiedl am See, Austria, October 2013. Springer, vol. 413, pp. 85-97.

Scholes, R.J., Walters, M., Turak, E., Saarenmaa, H., Heip, C.H.R., Tuama, É.Ó., Faith, D.P., Mooney, H.A., Ferrier, S., Jongman, R.H.G., Harrison, I.J., Yahara, T., Pereira, H.M., Larigauderie, A., Geller. G., 2012. Building a global observing system for biodiversity. Current Opinion in Environmental Sustainability 4(1), 139-146.

Science Communication Unit, University of the West of England, Bristol (2013). Science for Environment Policy In-depth Report: Environmental Citizen Science. Report produced for the European Commission DG Environment, December 2013. Available at: http://ec.europa.eu/science-environment-policy.

Sebald, C., Neubauer, G., Foitik, G., Flachberger, C., Lankmayr, G., Tellioglu, H., Havlik, D., Kluckner, S., 2014. The RE-ACTA Approach - Resilience Enhancement by Crowdsourcing and Crowdtasking. ISCRAM 2014 Conference.

Steed, C.A., Ricciuto, D.M., Shipman, G., Smith, B., Thornton, P.E., Wang, D., Shi, X., Williams, D.N., 2013. Big data visual analytics for exploratory earth system simulation analysis. Computers \& Geosciences 61 , 71-82.

Srirama, S.N., Jakovits, P., Vainikko, E., 2012. Adapting scientific computing problems to clouds using MapReduce. Future Generation Computer Systems 28(1), 184-192.

Sun, A., 2013. Enabling collaborative decision-making in watershed management using cloud-computing services. Environmental Modelling \& Software 41, 93-97. 
United Nations (UN), 2013. Sustainable Development Knowledge Platform; United Nations: New York, USA, 2013. http://sustainabledevelopment.un.org/

United Nations Initiative on Global Geospatial Information Management (UN-GGIM), 2013. Future

Trends in geospatial information management: the five to ten year vision, January 2013.

http://ggim.un.org/docs/Future-trends.pdf

Usländer, T., Jacques, P., Simonis, I., Watson, K., 2010. Designing environmental software applications based upon an open sensor service architecture. Environmental Modelling \& Software 25(9), 977-987.

Usländer, T., Berre, A., Granell, C., Havlik, D., Lorenzo, J., Sabeur, Z., Modafferi, S., 2013. The Future Internet Enablement of the Environment Information Space. In J. Hrebícek, G. Schimak, M. Kubásek, A.E. Rizzoli (Eds): Environmental Software Systems. Fostering Information Sharing (10th IFIP WG 5.11 International Symposium on Environmental Software Systems, ISESS 2013), Neusiedl am See, Austria, October 2013. Springer, vol. 413, pp. 109-120.

van der Zee, E., and Scholten, H., 2013. Application of geographical concepts and spatial technology to the Internet of Things. Research Memorandum 2013-33, Vrije University Amsterdam.

http://dare.ubvu.vu.nl/handle/1871/47951

Vitolo, C., Elkhatib, Y., Reusser, D., Macleod, C.J.A., 2015. Web technologies for environmental Big Data. Environmental Modelling \& Software 63, 185-198.

Wang, P., Wang, J., Chen, Y., Ni, G., 2013. Rapid processing of remote sensing images based on cloud computing. Future Generation Computer Systems 29(8), 1963-1968.

Wen, Y., Chen, M., Lu, G., Lin, H., He, L., Yue, S., 2013. Prototyping an open environment for sharing geographical analysis models on cloud computing platform. International Journal of Digital Earth 6(4), 356-382.

Yang, C., Goodchild, M., Huang, Q., Nebert, D., Raskin, R., Xu, Y., Bambacus, M., Fay, D., 2011. Spatial cloud computing: how can the geospatial sciences use and help shape cloud computing? International Journal of Digital Earth 4(4), 305-329.

Yang, C., Xu, Y., Nebert, D., 2013. Redefining the possibility of digital Earth and geosciences with spatial cloud computing. International Journal of Digital Earth 6(4), 297-312.

Zhang, Q., Cheng, L., Boutaba, R., 2010. Cloud computing: state-of-the-art and research challenges. Journal of Internet Services and Applications 1(1), 7-18. 